\title{
The Utility Of Earlobe Crease For The Detection Of Sub-Clinical Atherosclerosis.
}

\author{
La Utilidad Del Pliegue Del Lóbulo de la Oreja \\ Para la Detección de Aterosclerosis Subclínica.
}

Aldo F. Costa, MD

\begin{abstract}
Traditionally a crease in the ear has been considered a visible marker of atherosclerosis. There is strong evidence of its association with coronary heart disease (CHD) revealed in several retrospective and prospective studies. However, the usefulness of the earlobe crease (ELC) as a marker of atherosclerotic diseases of other vascular beds, especially in the intracranial or extracranial carotid vasculature, is not clear. A non-systematic search of studies evaluating the association between ELC and atherosclerosis was performed. Observational studies that explored the association of ELC with atherosclerosis in many vascular beds were reviewed. Most studies presented methodological limitations, selection bias, and relatively small sample sizes. Discrepancies were found between studies, mainly due to the interaction of age in the association pathway. In a population cohort study, age was the main modifier of the effect of ELC with atherosclerosis in different vascular beds. The role of ELC as a marker of atherosclerosis remains unclear, at least for extra-coronary atherosclerosis.

Keywords: Earlobe crease, atherosclerosis, cardiovascular diseases, cerebrovascular diseases.

\section{Resumen}

Tradicionalmente el pliegue del lóbulo de la oreja (PLO) ha sido considerado un marcador visible de aterosclerosis. Existe evidencia de su asociación con enfermedad coronaria, puesta de manifiesta en varios estudios tanto retrospectivos como prospectivos. Sin embargo, la utilidad del pliegue como marcador en enfermedades ateroscleróticas de otros lechos vasculares no es clara. Se realizó una búsqueda no sistemática de estudios que evalúen la asociación entre el PLO y aterosclerosis. Se encontraron estudios observacionales que exploraron la asociación de PLO con enfermedad aterosclerótica en varios lechos vasculares. La mayoría de estudios presentaron limitaciones metodológicas, sesgo de selección y tamaños muestrales relativamente pequeños. Se encontraron discrepancias entre los estudios, principalmente por la interacción de la edad en la vía de asociación. En un estudio de cohorte poblacional la edad fue el principal modificador del efecto del PLO con la aterosclerosis en los diferentes lechos vasculares. El rol del PLO como surrogado de aterosclerosis permanece sin dilucidarse, al menos para la aterosclerosis extra-coronaria.
\end{abstract}

Palabras clave: Pliegue de la oreja, aterosclerosis, enfermedades cardiovasculares, enfermedades cerebrovasculares.

\section{Instroduction}

Atherosclerosis is defined as the degeneration of the vascular wall because of aging and other factors that promote endothelial dysfunction. The inner wall of medium size and large vessels is covered by a layer of cells that function as a real endocrine tissue that takes parts in the regulation of biochemical processes that preserves the anti-thrombotic environment within vascular beds. ${ }^{2}$
Endothelial dysfunction plays a pivotal role in many pathophysiological processes that end in cardiovascular and cerebrovascular events. Before vascular diseases lead to clinical manifestations, asymptomatic changes progressively occur in vessels known as sub-clinical atherosclerosis. ${ }^{3}$

Introduction of modern imaging studies and surrogate biomarkers allows the detection of sub-clinical athe- 
rosclerosis., ${ }^{4,5}$ However, for underserved populations, the availability of such techniques might be limited or absent.

In this view, several inexpensive reliable markers of atherosclerosis have gained increasing interest in recent years. Population-based studies have evaluated several potential markers of asymptomatic atherosclerosis aimed to detect asymptomatic atherosclerotic degeneration and prevent vascular events in different settings. In Latin America, few population-based studies have addressed this issue and information is scarce. 6

Diagonal earlobe crease (ELC) first described by Frank has been historically appointed as a marker for coronary heart disease (CHD)? It is defined, in its classical pattern, as an appreciable diagonal wrinkle starting from ear tragus extending posteriorly to the free border of the earlobe in (Figure 1). Association with other atherosclerotic diseases remains controversial and evidence might be biased.

This review aims to present historical information about earlobe crease, its role as an atherosclerosis marker and to describe new results of a population-based study conducted in a rural Ecuadorian village.

\section{Searching Method}

A non-systematic review of the literature that included Medscape, EMBASE and Latindex databases was carried out, by the use of the following search terms: 1. ((Earlobe crease) OR (Diagonal earlobe crease) OR ("Frank's sign)) AND (atherosclerosis OR cardiovas-

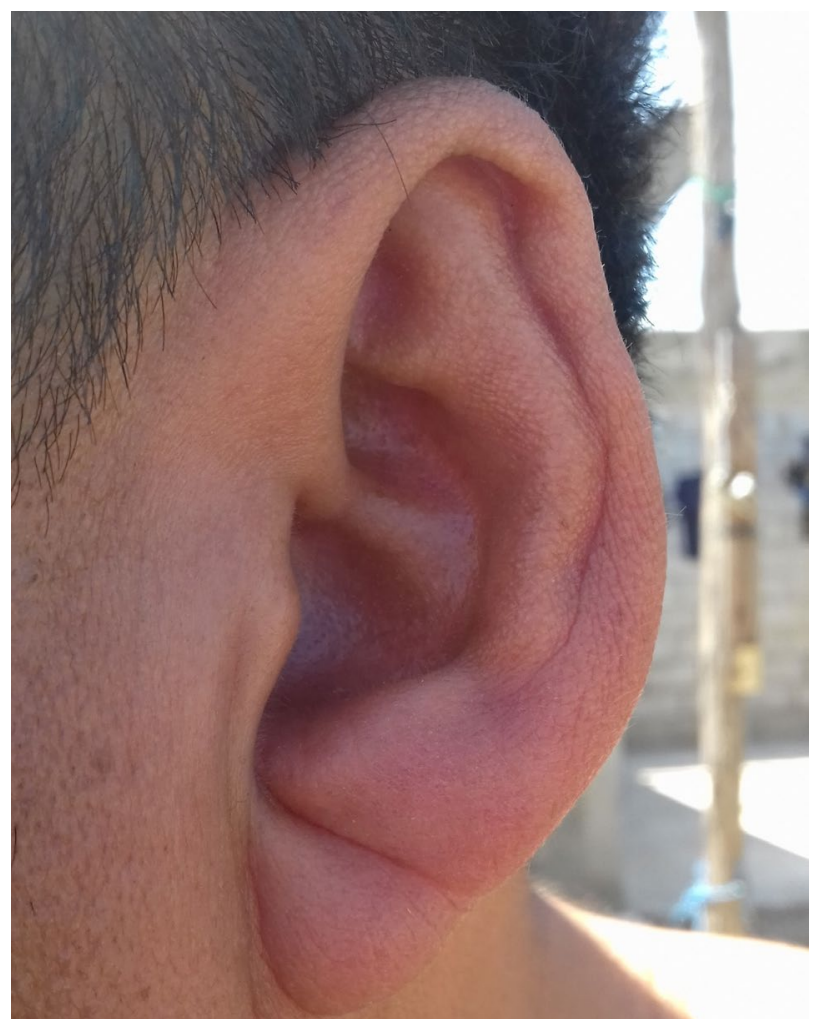

Figure 1. Diagonal earlobe crease extending from tragus to earlobe freeboard. cular disease) 2. ((Earlobe crease) OR (Diagonal earlobe crease) OR ("Frank's sign)) AND (Stroke OR cerebrovascular disease OR small vessel disease) 3. ((Earlobe crease) OR (Diagonal earlobe crease) OR ("Frank's sign)) AND "coronary heart disease." Articles written in English or Spanish were included with no article type restriction. References within the selected studies were also reviewed.

\section{Historical Perspective}

Frank described a diagonal ELC in 1979. In his paper, he noticed that 19 out of 20 consecutive patients with ELC presented one or more risk factors for CHD. However, identification of ELC in CHD comes from observations in antique Rome. Emperor Hadrian (76 to 138 A.D) governed Rome Empire from 117 to 138 A.D until his death in 138 A.D because of a long-standing chronic heart failure presumably of an atherosclerotic origin according to descriptions of historian Dio Cassius. In all the artistic representations of Emperor Hadrian, a diagonal earlobe crease is always present. In other paintings of Italian Renaissance art, an ELC can be appreciated in older people suggesting that ELC was a well-known sign of aging. ${ }^{10}$

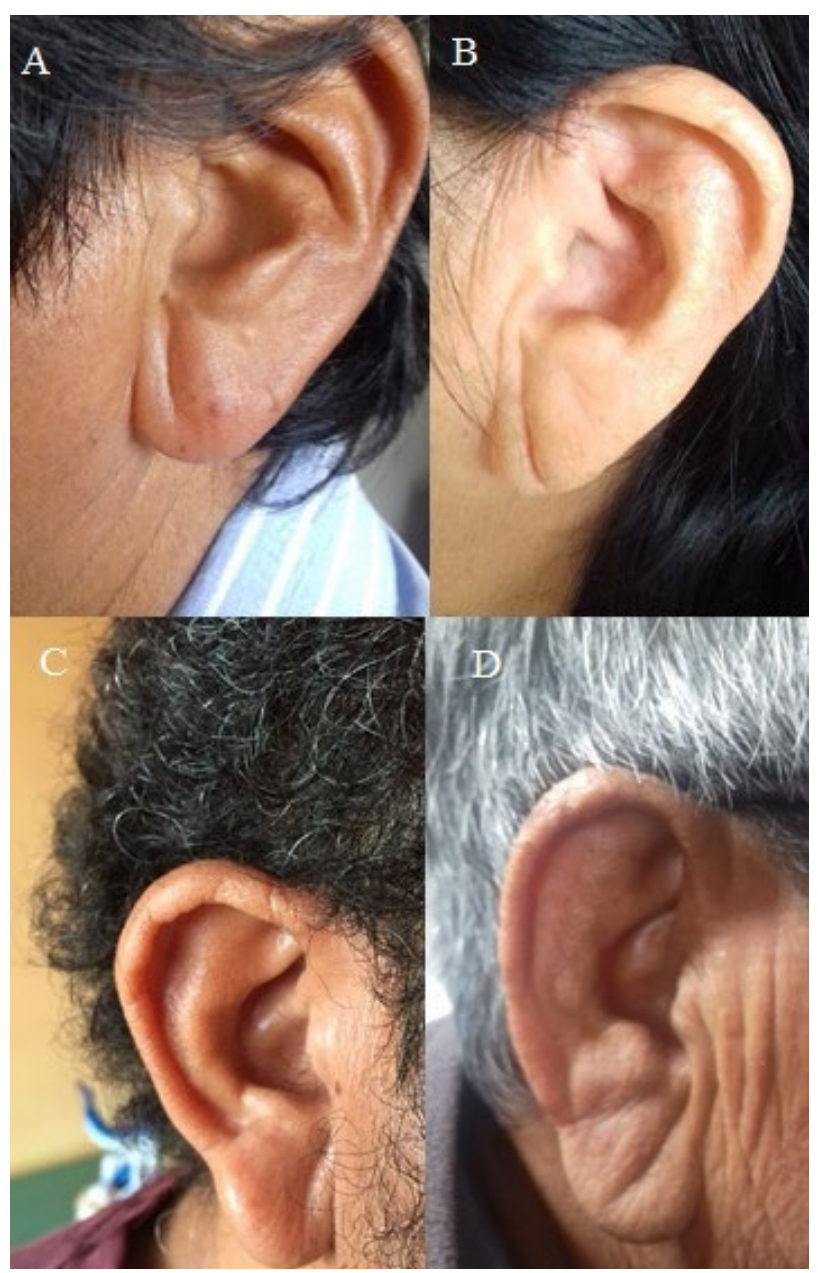

Figure 2. Earlobe crease variants. Vertical incomplete (A) and complete (B). Diagonal incomplete (C) and complete (D). 


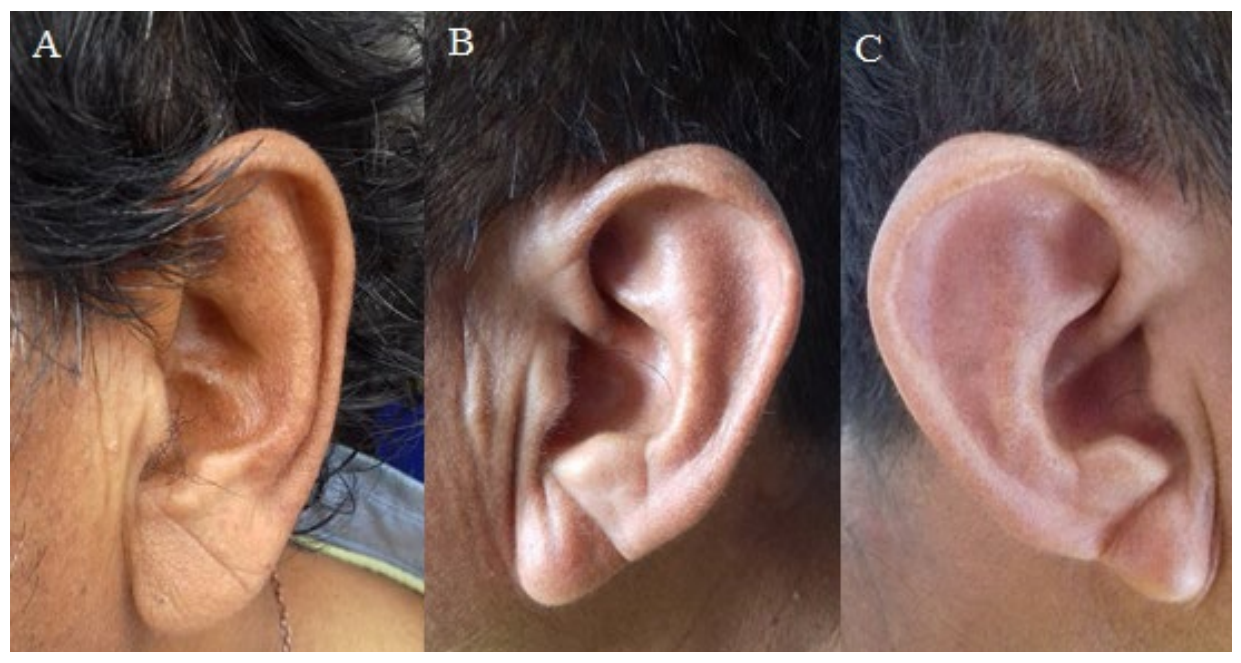

Figure 3. Ear lobe crease graded as: A) mild, B) moderate and C) severe.

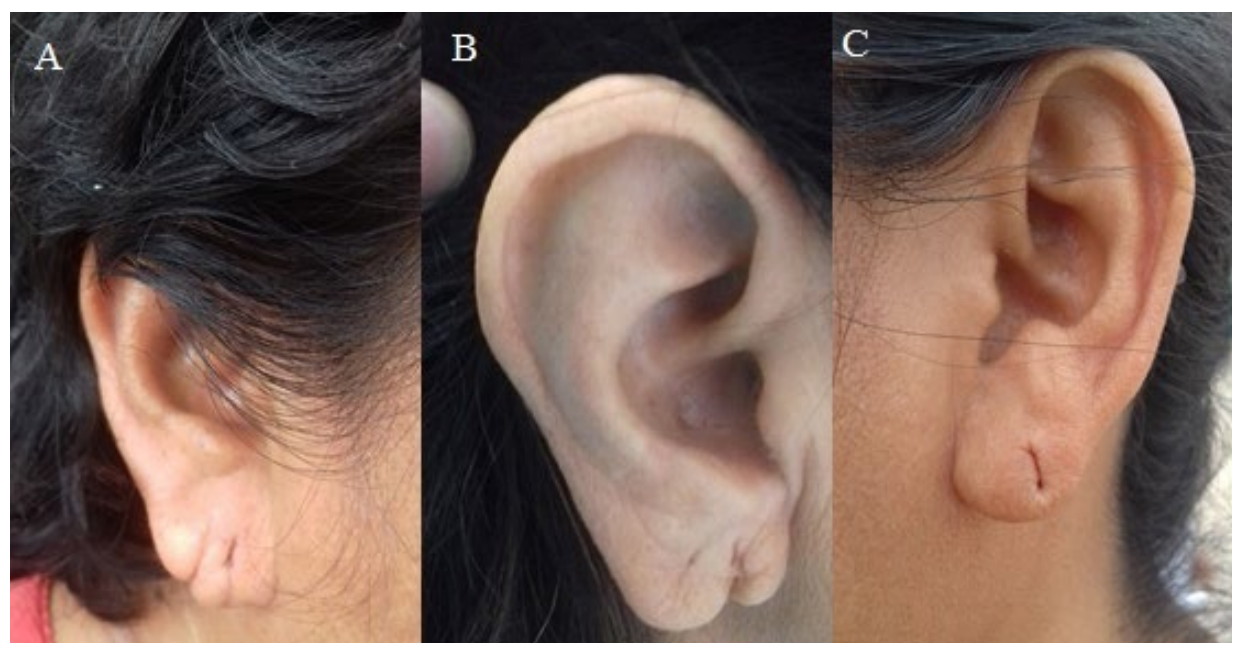

Figure 4. Earlobe unclassifiable morphology such as earlobe morphology variant $(A)$ malformation caused by earring use (B) and deep earring mark (C).

With these observations, it is likely that atherosclerosis is not a modern disease although; it is undebatable that the prevalence of atherosclerotic diseases, related to contemporary lifestyles, is increasing worldwide. Supporting this hypothesis, one study of 137 mummies of whom 34\% had any kind of atherosclerotic calcified arteries in computed tomography (CT) scans, suggested that unrecognized intrinsic factors other than lifestyle play a role in atherosclerosis. ${ }^{11}$ Interestingly, the mean age at death was 36 years old and was positively correlated with atherosclerosis.

\section{Epidemiology of Earlobe Crease}

It is well-known that the prevalence of ELC is directly proportional to age and is more prevalent in men than in women. ${ }^{12}$ The difference across races remains controversial given limited evidence.

Earlobe crease may be complete or incomplete, vertical or diagonal, unilateral or bilateral (Figure 2) and it can be categorized in mild, moderate and severe depending on the deepness of the crease (Figure 3).

However, a complete deep diagonal bilateral crease is the most common pattern used in current studies.
In a Chinese population, ELC prevalence was $62.4 \%$ and the mean age of the study population was 63 years..$^{13}$ In Japanese adults ELC prevalence was 9.7\%; the mean age was 52 years and prevalence of ELC increased with age. However, in a larger Japanese study with 3835 patients with a mean age of $48.46 \pm 11.60$ years, the prevalence was even higher $(20.89 \%) .^{14}$ A large study in Spain showed a bilateral ELC prevalence of $35 \%$ in patients aged 18 years or more (mean $67.5 \pm$ 16.5). ${ }^{15}$ In the Copenhagen City Heart Study, ELC prevalence ranged from $4 \%$ in the third decade of life to approximately $50 \%$ in men aged 70 years or more. Variability of prevalence could be related to poorly defined methods of crease classification and heterogeneous definition of ELC by each author.

In Ecuador, our group has explored the ELC in the general population using the Atahualpa Project, an ongoing cohort study. Atahualpa is a small village located in a rural coastal region of Ecuador with optimal characteristics for the practice of epidemiological studies. ${ }^{16,17}$

Seven hundred and nineteen residents from Atahualpa aged 40 or more were evaluated and photographs were obtained from 1438 ears. Of these 719 patients, 68 (9\%) wore earrings and were excluded (Figure 4). 
Among the remaining 651 patients, (mean age 59.5 \pm 12.7 years old; $50 \%$ men) $204(31 \%)$ had an ELC. ELC was more frequently bilateral (53\%), complete (54\%), mild (75\%) and diagonal (79\%). Only $22 \%$ and $4 \%$ were classified as moderate or severe crease, respectively. In $4 \%$ of patients ELC, the pattern of the crease was unclassifiable. Diagonal ELC was associated with increasing age ( $\beta$ coefficient: $0.037, \mathrm{p}=<0.001)$ and male sex (OR 2.5 , CI: $1.7-3.6 ; \mathrm{p}=<0.001)$ in our cohort.

\section{Potential Pathogenetic Pathways}

There is no accepted hypothesis that fully explains the interplay between ELC and atherosclerosis. Results from histopathological studies have shown degeneration of the elastin layer in individuals with ELC compared with individuals without it. This suggests a possible role for elastic fibers in the etiology of ELC. ${ }^{18}$ These changes in the earlobe might reflect similar changes in the elastic properties of the vessel wall. Another less accepted hypothesis states that irrigation of earlobe, as well as coronary circulation, is terminal and lacks from collaterals resulting in the chronic degenerative process.

However, some studies have shown that bilateral ELC but not unilateral crease associates with atherosclerosis and endothelial dysfunction, complicating, even more, the understanding of a possible pathogenetic pathway. ${ }^{19-21}$ There are no longitudinal data that explores the rationale behind this observation thus, ELC and atherosclerosis could be merely a coincidence of two processes product of aging.

Four post-mortem studies had evaluated the association between coronary atherosclerosis and ELC. Cumberland and colleagues reported the first one in 1987. They evaluated 800 consecutive autopsies and determined a significant association between the presence of the diagonal crease and coronary atherosclerosis defined as a narrowing on at least one major coronary artery greater than $75 \%{ }^{22}$

After that report, three more autopsies studies (sample size ranges from 100 to 520 subjects) found that ELC was not only significantly associated with coronary atherosclerotic disease but the strongest risk factor for coronary heart disease, cardiovascular death independently of age. . $^{23-25}$

Taking all this evidence together, it is difficult to define a definitive pathway that fully explains this association and perhaps those associations rely on multiple causal pathways.

\section{Earlobe Crease And Its Association With Coronary Heart Disease}

Since Frank's first report several studies including post-mortem, cross-sectional, case-control studies, prospective studies, and even systematic reviews have addressed the association between ELC and CHD.

Autopsies reports have consistently confirmed a positive association between the earlobe and coronary arteries narrowing. One post-mortem study examined 800 corpses and found a positive correlation between the presence of the diagonal earlobe crease and $>75 \%$ of lumen obstruction in at least one major coronary artery.22 Other smaller post-mortem studies showed an independent association between the earlobe and coronary atherosclerosis. ${ }^{23-25}$

In one case-control study that recruited 100 cases and 100 control subjects, the presence of ELC (unilateral or bilateral) increased the odds of having angiographic proven CHD by 5.63 (CI 95\%: 2.917-10.938; $\mathrm{p}=$ $<0.00)$. Nonetheless, controls were selected from surgical, medical and neurology units of the hospital and CHD were ruled out based only on patient interview and examination. ${ }^{26}$ Other case-control studies compared ELC presence in 100 patients. Fifty subjects from each group were recruited through convenience sampling. ELC was more prevalent in patients with $\mathrm{CHD}(\mathrm{p}=<0.05)$. In a multivariate logistic regression left ELC did not reach statistical significance for CHD prediction (OR: 1.02, CI 95\%: $1.00-1.04 ; \mathrm{p}=0.047) .^{27}$ No angiography was performed in controls of any of the previously described studies. Thus, classification and Berkson's bias could be present, and those results should be taken with caution.

In 1996, Elliot et. al. described the results of a prospective study with patients admitted to the coronary unit. Baseline information such as earlobe crease (no crease, unilateral, bilateral), demographics, anthropometrics, prior myocardial infarction (MI) and traditional risk factors (hypertension, diabetes, obesity, family history) was obtained from medical records. Over 10 years, 96 cardiac deaths occurred $(24 \%, 36 \%$, and $46 \%$ of the 0,1 and 2 ELC, respectively). Adjusted-Cox proportional hazards showed an independent association of ELC with cardiac events (OR: 1.53, 95\% CI: $1.06-2.20 ; p=0.02)$. Remarkable aspects of this study are the prospective design and the age-independent association. Moreover, in a subset of patients undergoing angiography, the number of ELC was positively correlated with the number of coronary diseased arteries.

Wu, et al. replicated the 1996 Elliot study with a similar methodology in Chinese population. ${ }^{13}$ Four hundred forty-nine subjects including 199 subjects without coronary artery disease (CAD) and 250 cases of CAD were prospectively enrolled. All of them underwent cardiac catheterization at baseline. People with earring or piercing marks were excluded. In univariate analysis $(\mathrm{p}=<0.001)$ and multivariate analysis (OR: 3.41, 95\% CI: 2.24 - 5.20; p $<0.001)$ ELC was an independent predictor of CHD.

\section{Earlobe Crease And Extra-Coronary Atherosclerosis}

Since ELC correlates with coronary artery disease, it would be interesting to explore its association with atherosclerosis at different vascular beds. The present review focuses on carotid atherosclerosis and peripheral artery disease. Cerebrovascular disease and ELC association including intracranial atherosclerosis are discussed separately. 
Earlobe crease and carotid intima-media thickness

Five studies have addressed this relationship between ELC and carotid intima-media thickness (cIMT), three cross-sectional and two case-control studies. All of them showed positive results regarding the association. Despite, positive results some limitations could potentially biased results. Çelik et. al recruited 130 (65 cases and 65 controls) ${ }^{28}$ The cIMT was measured in the common carotid artery (CCA) at $1 \mathrm{~cm}$ of bifurcation. The cIMT was higher in patients with ELC compared to controls $(0.88 \pm 0.14$ vs. $0.69 \pm 0.14 \mathrm{~mm}$, respectively, $\mathrm{p}=0.0001$ ). For statistical analysis, the authors used unpaired sample tests despite the case-control design. In multivariate analysis, authors only mention that cIMT was independently associated with ELC in the multivariate analysis, but no odds ratios or $p$ values are reported. Moreover, authors stratified individuals by age groups and conclude that "in the age groups, no significant difference was noted in carotid IMT between ELC cases and controls", but all p values for each age group comparison was significant. It is not clear what authors meant with that conclusion regarding age stratification analysis.

Glavic et. al carried out another case-control study with 60 subjects ( 30 cases and 30 controls) and measured the cIMT in the CCA, at $1.5 \mathrm{~cm}$ of bifurcation. ${ }^{29}$ Authors analyzed cIMT as a categorical data and compared with ELC using Chi-square test (X2=1,279; $\mathrm{p}=0.001)$. McNemar's test, a paired sample test, to detect distribution differences across groups could be more appropriate for such comparison.

Ziyrek et. al conducted a cross-sectional study with 130 patients.$^{30}$ cIMT was measured in CCA, at $1 \mathrm{~cm}$ of bifurcation. The authors determined that IMT was higher in the ELC group $(0.85 \pm 0.16$ vs. $0.60 \pm 0.15 ; \mathrm{p}<0.0001)$ and found an independent association in regression analysis. Shrestha et. al, as well as Rerkimitr et. al, also evaluated association between ELC and cIMT using a cross-sectional design in 212 and 147 patients, respectively. In both studies cIMT was only measured in the CCA, $10 \mathrm{~mm}$ proximal to carotid bulb. In the first mentioned study, patients with ELC had significantly higher carotid cIMT than controls $(0.90 \pm 0.24$ vs $0.77 \pm 0.15, \mathrm{p}<0.001){ }^{31}$ whereas in the other one, no association with cIMT was found in the diagonal ELC sub-group despite the fact that cIMT was higher in anterior tragal crease group $(0.79 \pm 0.25 \text { vs. } 0.66 \pm 0.10 \text { [no p-value reported] })^{32}$

As disclosed by authors, relatively small sample size, selection bias, limited assessment of the cIMT, and heterogeneity of cIMT cutoff values account for major limitations of these studies.

Recently, the Atahualpa cohort study explored the possible association between cIMT at the population level $3^{33}$ Community dwellers aged 40 or more were asked to participate and 594 were included. In general, we found a statistically significant association between ELC and increased cIMT (OR, 1.67; 95\% IC 1.04 - 2.69; $\mathrm{p}=0.033$ ) which disappeared when age and cardiovascular risk factors were added to multivariate models. Despite previous studies, age and cardiovascular risk factors were better predictors of cIMT increase than ELC by itself.

\section{Earlobe crease and atherosclerosis of peripheral arteries}

Korkmaz et al. assessed the association of ELC and vascular parameters of peripheral resistance in two separate studies.

The first one consisted of 180 asymptomatic hypertensive patients: 75 with ELC and the remaining 75 without ELC ${ }^{34}$ Cardiac-ankle vascular index (CAVI) in both groups was measured and the mean was compared between them.

The authors found a statistically significant difference of CAVI in those patients with ELC compared to those who did not have ELC $(9.8 \pm 2.1$ vs. $8.6 \pm 1.6, \mathrm{p}<0.001)$. Linear regression analysis demonstrated ELC (95\% CI: $0.61-1.74$, $\mathrm{p}=0.009)$, age (95\% CI: $0.03-0.09, \mathrm{p}<0.001)$ and male gender (95\% CI: $0.48-1.55, \mathrm{p}=0.03)$ as independent risk factors of CAVI. Authors state that changes in the ratio of collagen to elastin, a mechanism believed to explain elastic changes in the earlobe, might be a possible explanation for increased arterial stiffness in subjects with ELC.

The second study explored the association between peripheral artery disease (PAD) defined as an $\mathrm{ABI}<1.0$ and the presence of ELC in 253 consecutive patients from hospital cohort (mean age $71 \pm 10$ ). ${ }^{35}$

Patients with PAD $(n=56 ; 22 \%)$ had a higher prevalence of ELC than individuals with normal Ankle-Brachial Index (ABI). ABI values in patients with ELC were lower than without ELC $(1.06 \pm 0.12$ vs $1.11 \mathrm{v} 0.12, \mathrm{p}<$ $.001)$. The ELC (95\% CI: 3.3-21.9; $\mathrm{p}=0.001)$ and age (95\% CI: 0.87-0.99; $p=0.02$ ) were independent determinants of abnormal $\mathrm{ABI}$ in multivariate logistic regression.

The authors also stratified the whole sample into four groups according to their ABI measurement. Thus, 98 were categorized as normal (ABI 1.1-1.29), 99 as lower normal (ABI 1.0-1.09), 38 as borderline PAD (ABI 0.9-0.99) and 18 as true PAD. Total cohort ELC prevalence was $53.8 \%$ $(\mathrm{n}=136)$ and the prevalence of ELC increased with ABI.

In the Atahualpa Project, 294 patients underwent earlobe and ABI evaluation ${ }^{36}$ We could not find an independent association between ELC and ABI. Using adjusted logistic regression models, there was no association between ELC and abnormal ABI (OR: 1.71; 95\% CI: 0.89 $-3.26 ; p=0.104)$. In line with other findings in this population, age was the only significant covariate $(\mathrm{p}<0.001)$. These results might not be comparable with previously mentioned studies because of different ABI cutoff value for defining PAD. Compared with other studies strengths of our study were a relatively small chance of selection 
bias and a larger number of patients. However, as in other findings from the Atahualpa Project, results cannot be extrapolated to other different populations.

\section{Earlobe Crease And Cerebrovascular Disease}

Studies about ELC and cerebrovascular diseases (CVD) are heterogeneous and inconclusive. Case reports have revealed the coexistence of cerebrovascular disease in the form of atherosclerosis of intracranial arteries or overt stroke ${ }^{37,38}$ However, the mere coexistence of two factors does not imply association, much less causation.

Based on these first anecdotal descriptions, various higher-quality studies have been carried out evaluating the association of CVD and ELC.

First, our group evaluated the association of calcifications of the carotid siphon as a marker of intracranial atherosclerosis and the presence of ELC. In this series of 651 subjects in the community, the ELC was marginally associated with intracranial atherosclerosis $(p=0.06)$ in univariate regression models. This non-significant association disappeared completely when age was introduced to the model. Despite the relatively large sample, the ethnicity of these patients may suggest that results of this study cannot be extrapolated to other populations of a different ethnic origin. However, the results of this study propose age as an important confounding factor when assessing the association between ELC and CVD. ${ }^{39}$

Studies found in the literature range from case reports to cross-sectional studies with prospective patient recruitment. Most studies have methodological limitations that make their results difficult to interpret (Table).

Such is the case of studies with selection bias (including only patients with stroke $){ }^{40}$ small sample size ${ }^{41,42}$ and methodological deficiencies such as applying statistical tests to independent samples after matching cases with hospital controls.

There is the only study that included a significant number of patients $(n=1000)$ to find differences in CDV distribution between the group with ELC and without ELC. ${ }^{43}$ This study showed a significant association in both univariate and multivariate analyses. However, even though patients were recruited consecutively for the evaluation of ELC, clinical data including history of cardiovascular diseases were obtained from hospital's medical records. Confirmation of clinical manifestations or imaging findings was not reported potentially overestimate CVD rates.

Cerebral small vessel disease, a heterogeneous subtype of stroke which affects small vessels and capillaries of the brain, is an under-recognized etiology of cognitive decline and dementia. ${ }^{44,45}$ Its relative high prevalence in South American populations has raised the interest in the

Table 1. Studies addressing ELC and cerebrovascular disease association.

\begin{tabular}{|c|c|c|c|c|}
\hline Author (year) & Article type & Sample & Results & Limitations \\
\hline $\begin{array}{l}\text { Zapata-Wainberg et al. } \\
(2013) 38\end{array}$ & Case report & 1 patient & $\begin{array}{l}\text { A left posterior cerebral } \\
\text { artery stroke in a patient } \\
\text { with ELC. }\end{array}$ & $\begin{array}{l}\text { Descriptive single } \\
\text { patient report. }\end{array}$ \\
\hline $\begin{array}{l}\text { Rodriguez-Lopez et al. } \\
\text { (2015)43 }\end{array}$ & $\begin{array}{l}\text { Cross-sectional } \\
\text { prospective. }\end{array}$ & $\begin{array}{l}\mathrm{N}=1000 ; 349(34.9 \%) \\
\text { with bilateral ELC. }\end{array}$ & $\begin{array}{l}\text { IS: } 19 \% \text { vs. } 10 \% \\
(p=<0.001) ; \text { HS: } 3 \% \text { vs } \\
2 \%(p=0.7) \text { and TIA: } 7 \% \\
\text { vs } 5 \%(p=0.19) . \\
\text { Significant association } \\
\text { only with IS in univariate } \\
\text { (OR 1.97[1.41-75]; } \\
p=<0.001) \text { and } \\
\text { multivariate regression } \\
\text { (OR 1.67[1.1-2.51]; } \\
p=0.015) .\end{array}$ & $\begin{array}{l}\text { Information bias and } \\
\text { real cardiovascular } \\
\text { state not investigated. }\end{array}$ \\
\hline Nazzal et al.(2017)40 & $\begin{array}{l}\text { Cross-sectional } \\
\text { prospective. }\end{array}$ & $\begin{array}{l}\mathrm{N}=241 \text { stroke/TIA } \\
\text { patients; } 190(78.8 \%) \\
\text { with ELC. }\end{array}$ & $\begin{array}{l}\text { Frank's sign prevalence } \\
\text { among stroke patients: } \\
88.6 \% \text { and in TIA } \\
\text { patients: } 73.2 \% \text {. }\end{array}$ & $\begin{array}{l}\text { No comparison between } \\
\text { stroke and non-stroke } \\
\text { subjects. }\end{array}$ \\
\hline Levine et al. (1993)41 & $\begin{array}{l}\text { A prospective study, } \\
\text { preliminary results. }\end{array}$ & $\begin{array}{l}\mathrm{N}=348 ; 116 \text { stroke } \\
\text { patients and } 232 \\
\text { non-stroke controls. }\end{array}$ & $\begin{array}{l}135(39 \%) \text { presented } \\
\text { ELC. IS was present in } \\
50 \% \text { of patients with ELC } \\
\text { compared to } 22 \% \text { in } \\
\text { patients without ELC } \\
(p=<0.005) .\end{array}$ & $\begin{array}{l}\text { Unpaired statistical } \\
\text { tests used for the paired } \\
\text { sample. No multivariate } \\
\text { analysis performed. } \\
\text { Small sample size with } \\
\text { few cases. }\end{array}$ \\
\hline Korkmaz(2018)42 & $\begin{array}{l}\text { Cross-sectional } \\
\text { perspective. }\end{array}$ & $\begin{array}{l}\mathrm{N}=285 ; 52(19 \%) \\
\text { with WMH and } 233 \\
(81 \%) \text { without WMH. }\end{array}$ & $\begin{array}{l}\text { Higher prevalence of } \\
\text { WMH in subjects with } \\
\text { ELC }(p<0.001) \text {. } \\
\text { Multivariate model } \\
\text { showed an independent } \\
\text { association of ELC and } \\
\text { WMH }(\mathrm{Cl}: 0.098-0.783 ; \\
p<0.001)\end{array}$ & $\begin{array}{l}\text { Direction and } \\
\text { magnitude of } \\
\text { association were not } \\
\text { reported. }\end{array}$ \\
\hline
\end{tabular}

Abbreviations: IS, ischemic stroke; HS, hemorrhagic stroke; TIA, transient ischemic attack; $\mathrm{Cl}$, confidence intervals; OR, odds ratio; WMH, white matter hyperintensities 
search for biomarkers that effectively selects candidates for the practice of neuroimaging studies. ${ }^{46}$

In this view, using the Atahualpa Project, we aimed to evaluate the association between cognitive decline and ELC in 629 dwellers. Patients with ELC presented worse cognitive performance as evaluated by the Montreal Cognitive Assessment $(\mathrm{p}=0.001)$. However as described above, the introduction of age in the model made such significance to disappear47. In contrast with our findings, Lee et al. published results from a cross-sectional hospital-based study including 714 Korean patients (243 with normal cognition and 471 with impaired cognition). The presence of ELC was positively associated with cognitive impairment in univariate $(\mathrm{p}<0.001)$ and multivariate-adjusted models $(p=0.007)$. Categories of cognitive impairment were also associated with univariate models with ELC, but only dementia (vs. normal cognition) showed a significant association in multivariate models. Taking into consideration the dementia etiology ELC was independently associated with vascular dementia, but not Alzheimer's disease. Patients with cognitive impairment were regrouped in a factorial fashion according to the positivity of amyloid- $\beta$ (A $\beta$ ) on positron emission tomography (PET) and white matter lesions severity. The presence of ELC increased 7-fold the odds of having severe white matter lesions and positive $A \beta$ combination even after adjusting for age $(p<0.001)$. Such discrepancies with the results of the Atahualpa project perhaps rely on different ethnic origin populations. Further studies that better explores the role of ELC in small vessel disease are needed.

\section{Conclusion}

ELC seems to be an independent marker of coronary atherosclerosis demonstrated in several studies. However, its association with atherosclerosis involving other vascular beds remain controversial. Results from a cohort study in Amerindians have shown an important interaction of age in the association between ELC and atherosclerosis in the carotid arteries, intracranial arteries, and $\mathrm{ABI}$ in contrast with other relative small sample studies conducted in different populations where the association is independent of age. The role of ELC in cerebrovascular disease is even more obscure given the scarcity of the data regarding this association. Large cross-sectional study found a significant correlation between ELC and cognitive decline, as well as, with markers of small vessel disease in the brain. However, other population-based study attributed this association to older age. These findings support the hypothesis that atherosclerosis may obey to different pathogenetic mechanisms in different parts of the vascular tree, but there is no sufficient evidence to state that ELC is a marker only for CHD and no for atherosclerosis in other vascular beds. More studies are needed to establish the role of ELC in extra-coronary atherosclerosis.

\section{References}

1. Hansson, G. K. Inflammation, atherosclerosis, and coronary artery disease. N. Engl. J. Med. 352, 1685-1695 (2005).

2. Ungvari, Z. et al. Endothelial dysfunction and angiogenesis impairment in the ageing vasculature. Nat. Rev. Cardiol. 15, 555-565 (2018).

3. Bisoendial, R. J. et al. Measurement of subclinical atherosclerosis: beyond risk factor assessment. Curr. Opin. Lipidol. 13, 595-603 (2002).

4. Sillesen, H. et al. Carotid plaque burden as a measure of subclinical atherosclerosis: comparison with other tests for subclinical arterial disease in the High Risk Plaque Biolmage study. JACC Cardiovasc. Imaging 5, 681-689 (2012).

5. Naqvi, T. Z. \& Lee, M.-S. Carotid intima-media thickness and plaque in cardiovascular risk assessment. JACC Cardiovasc. Imaging 7, 1025-1038 (2014).

6. Del Brutto, O. H. et al. The Search Of Surrogates For Neuroimaging Studies For Research Purposes: The Atahualpa Project Experience. Rev. Ecuat. Neurol. 26, 128-134.

7. Frank, S. T. Aural sign of coronary-artery disease. N. Engl. J. Med. 289, 327-328 (1973).

8. Christoffersen, M. \& Tybjærg-Hansen, A. Visible aging signs as risk markers for ischemic heart disease: Epidemiology, pathogenesis and clinical implications. Ageing Res. Rev. 25, 24-41 (2016).

9. Petrakis, N. L. Diagonal earlobe creases, type A behavior and the death of Emperor Hadrian. West. J. Med. 132, 87-91 (1980).

10. Galassi, F. M. et al. Palaeopathology of the earlobe crease (Frank's sign): New insights from Renaissance art. Int. J. Cardiol. 236, 82-84 (2017).

11. Thompson, R. C. et al. Atherosclerosis across 4000 years of human history: the Horus study of four ancient populations. Lancet Lond. Engl. 381, 1211-1222 (2013).

12. Wu, X.-L., Yang, D.-Y., Zhao, Y.-S., Chai, W.-H. \& Jin, M.-L. Diagonal earlobe crease and coronary artery disease in a Chinese population. BMC Cardiovasc. Disord. 14, 43 (2014).

13. Wu, X.-L., Yang, D.-Y., Zhao, Y.-S., Chai, W.-H. \& Jin, M.-L. Diagonal earlobe crease and coronary artery disease in a Chinese population. BMC Cardiovasc. Disord. 14, 43 (2014).

14. Kang, E. H. \& Kang, H. C. Association Between Earlobe Crease and the Metabolic Syndrome in a Crosssectional Study. Epidemiol. Health 34, e2012004 (2012).

15. Rodríguez-López, C. et al. Earlobe Crease Shapes and Cardiovascular Events. Am. J. Cardiol. 116, 286-293 (2015).

16. Del Brutto, O. H. et al. Door-to-door survey of major neurological diseases in rural Ecuador--the Atahualpa Project: methodological aspects. Neuroepidemiology 23, 310-316 (2004).

17. Del Brutto, O. H., Mera, R. M., Castillo, P. R. \& Del Brutto, V. J. Key findings from the Atahualpa Project: what should we learn? Expert Rev. Neurother. 18, 5-8 (2018).

18. Elliott, W. J. \& Karrison, T. Increased all-cause and cardiac morbidity and mortality associated with the dia- 
gonal earlobe crease: a prospective cohort study. Am. J. Med. 91, 247-254 (1991).

19. Oda, N. et al. Relation of the Bilateral Earlobe Crease to Endothelial Dysfunction. Am. J. Cardiol. 119, 19831988 (2017).

20. Evrengül, H. et al. Bilateral diagonal earlobe crease and coronary artery disease: a significant association. Dermatol. Basel Switz. 209, 271-275 (2004).

21. Iorgoveanu, C., Zaghloul, A., Desai, A., Krishnan, A. M. \& Balakumaran, K. Bilateral Earlobe Crease as a Marker of Premature Coronary Artery Disease. Cureus 10, e2616 (2018).

22. Cumberland, G.D., Riddick,L. \& Vinson, R. Earlobe creases and coronary atherosclerosis. The view from forensic pathology. Am. J. Forensic Med. Pathol. 8, 9-11 (1987).

23. Ishii, T. et al. Earlobe crease and atherosclerosis. An autopsy study. J. Am. Geriatr. Soc. 38, 871-876 (1990).

24. Edston, E. The earlobe crease, coronary artery disease, and sudden cardiac death: an autopsy study of 520 individuals. Am. J. Forensic Med. Pathol. 27, 129-133 (2006).

25. Patel, V. et al. Diagonal earlobe creases and atheromatous disease: a postmortem study. J. R. Coll. Physicians Lond. 26, 274-277 (1992).

26. Kamal, R. et al. Diagonal Earlobe Crease as a Significant Marker for Coronary Artery Disease: A Case-control Study. Cureus 9, el013 (2017).

27. Kwai-Ping Suen, L., Lau, Y.-K., Ma, H.-C., Lai, K.-W. \& Holroyd, E. Predictive value of auricular diagnosis on coronary heart disease. Evid.-Based Complement. Altern. Med. ECAM 2012, 706249 (2012).

28. Celik, S., Erdoğan, T., Gedikli, O., Kiriş, A. \& Erem, C. Diagonal ear-lobe crease is associated with carotid intimamedia thickness in subjects free of clinical cardiovascular disease. Atherosclerosis 192, 428-431 (2007).

29. Glavic, J., Cerimagic, D., Lovrencic-Huzjan, A., Vukovic, V. \& Demarin, V. Frank's sign as a risk factor for cerebrovascular disease. Atherosclerosis 196, 477-478 (2008).

30. Ziyrek, M., Şahin, S., Özdemir, E., Acar,Z.\& Kahraman, S. Diagonal earlobe crease associated with increased epicardial adipose tissue and carotid intima media thickness in subjects free of clinical cardiovascular disease. Turk Kardiyol. Dernegi Arsivi Turk Kardiyol. Derneginin Yayin Organidir 44, 474-480 (2016).

31. Shrestha, I. et al. Diagonal ear-lobe crease is correlated with atherosclerotic changes in carotid arteries. Circ. J. Off. J. Jpn. Circ. Soc. 73, 1945-1949 (2009).

32. Rerknimitr, P. et al. Anterior Tragal Crease Is Associated With Atherosclerosis: A Study Evaluating Carotid Artery Intima-Media Thickness. Angiology 68, 683-687 (2017).

33. Del Brutto, O. H., Mera, R. M., Costa, A. F., Castillo, P. R. \& Matcha, G. On the association between earlobe crease and the carotid intima-media thickness: A population-based study. Heliyon 5, e01556 (2019).
34. Korkmaz, L. et al. Association between Diagonal Earlobe Crease and Cardio-Ankle Vascular Index in Asymptomatic Hypertensive Patients. Med. Princ. Pract. 22, 530-534 (2013).

35. Korkmaz, L. et al. Earlobe Crease May Provide Predictive Information on Asymptomatic Peripheral Arterial Disease in Patients Clinically Free of Atherosclerotic Vascular Disease. Angiology 65, 303-307 (2014).

36. Del Brutto, O. H., Mera, R. M., Costa, A. F., Zambrano, M. \& Sedler, M. J. The Association between Earlobe Crease (Frank's Sign) and Abnormal Ankle-Brachial Index Determination Is Related to Age: A PopulationBased Study. Int. J. Vasc. Med. 2018, 1-4 (2018).

37. Del Brutto, O. H. \& Costa, A. F. Diagonal Earlobe Crease Revealing Intracranial Atherosclerosis. J. Neurosci. Rural Pract. 9, 256-257 (2018).

38. Zapata-Wainberg, G. \& Vivancos, J. Bilateral Earlobe Creases. N. Engl. J. Med. 368, e32 (2013).

39. Del Brutto, O. H., Costa, A. F. \& Mera, R. M. Intracranial Atherosclerosis And The Earlobe Crease (Frank's Sign). A Population Study. Rev. Ecuat. Neurol. 27, 20-24 (2018).

40. Nazzal, S., Hijazi, B., Khalila, L. \& Blum, A. Diagonal Earlobe Crease (Frank's Sign): A Predictor of Cerebral Vascular Events. Am. J. Med. 130, 1324.el-1324.e5 (2017).

41. Levine, R. L. \& Daly, R. F. Diagonal earlobe creases and ischemic stroke: Preliminary report. J. Stroke Cerebrovasc. Dis. 3, 106-111 (1993).

42. Korkmaz, H. A. A. Relationship between the earlobe crease and brain white matter abnormalities in apparently healthy subjects. Turk J Med Sci 6.

43. Rodríguez-López, C. et al. Earlobe Crease Shapes and Cardiovascular Events. Am. J. Cardiol. 116, 286-293 (2015).

44. Pantoni, L. Cerebral small vessel disease: from pathogenesis and clinical characteristics to therapeutic challenges. Lancet Neurol. 9, 689-701 (2010).

45. de Groot, J. C. et al. Cerebral white matter lesions and cognitive function: the Rotterdam Scan Study. Ann. Neurol. 47, 145-151 (2000).

46. Del Brutto, O. H., Mera, R. M., Del Brutto, V. J., Zambrano, M. \& Lama, J. White matter hyperintensities of presumed vascular origin: a population-based study in rural Ecuador (The Atahualpa Project). Int. J. Stroke Off. J. Int. Stroke Soc. 10, 372-375 (2015).

47. Del Brutto, O. H., Mera, R. M., Zambrano, M. \& Costa, A. F. The association between earlobe crease (Frank's sign) and cognitive performance is related to age. Results from the Atahualpa Project. Arch. Gerontol. Geriatr. 79, 104-107 (2018).

Acknowledgments: Dr. Oscar H. Del Brutto who contributed with unpublished original data and pictures for this review.

Disclosure: Nothing to disclose.

Funding: None. 